\title{
Contribuição ao estudo sobre as relações entre Colonialismo e a Antropologia Social
}

\section{Zanoni Neves}

Coordenador do Museu Antropológico do Vale do São Francisco. Coordenador do Núcleo de Estudos do Vale do São Francisco. Mestre em Antropologia Social (Unicamp). Belo Horizonte [MG] Brasil <zanonineves@ig.com.br>.

\section{Resumo}

Este artigo é uma breve contribuição ao estudo sobre as relações entre o colonialismo e a Antropologia Social em suas origens. Os antropólogos contribuíram para o treinamento de agentes e funcionários coloniais, mas certamente o ensino do conhecimento antropológico evitou traumas coletivos nos contatos entre os colonos e os nativos. Richard Francis Burton trabalhou como agente do Império Britânico, mas legou preciosos relatos de viagens para as Ciências Humanas e Ambientais.

\section{Palavras-chave}

Colônias. Treinamento. Funcionários coloniais. Conflito. Ideologia colonialista.

\section{Contribution to the study about the relations between the Colonialism and the Social Anthropology}

\begin{abstract}
This article intends to research the relations between the colonialism and the Social Anthropology in its origins. The anthropologists contributed to the training of colonial agents and officers, but certainly the teaching of the anthropological knowledge prevented collective traumas in the contacts between the colonists and the natives. Richard Francis Burton was un agent of the British Empire, but he left precious statements of voyages to the Human and Ambiental Sciences.
\end{abstract}

\section{Keywords}

Colonies. Training. Colonial agents and officers. Conflict. Colonialist ideology. 


\section{Introdução}

Este artigo é uma breve reflexão sobre as origens da Antropologia Social, tendo como bibliografia básica a obra de Adam Kupper (1978). A nosso ver, esse é um dos autores que abordaram o referido tema com isenção e imparcialidade. Mas o nosso estudo inclui também a obra de Richard Francis Burton (1977) sem perder de vista sua biografia, escrita por Edward Rice (1993).

A tentativa de desvincular as origens da Antropologia Social de práticas coloniais e/ou da ideologia colonialista é uma tentativa vã, a nosso ver. Uma ciência pode surgir e/ou desenvolver-se a partir de uma ideologia e da prática que lhe corresponde. Ao longo do tempo, entretanto, pode criar, desenvolver, refinar e reelaborar sua metodologia de pesquisa - seus conceitos, noções e categorias analíticas - sem perder de vista a experiência prática no trabalho de campo. Nenhuma ciência nasce pronta. Até mesmo depois de amplamente desenvolvido o seu instrumental teórico e metodológico, muitas bebem em fontes descritivas que as precedem e, até mesmo, no saber popular e/ou de grupos étnicos, com o qual se defrontam, para avançar no processo acumulativo do conhecimento conforme já o demonstramos em outra oportunidade (Neves, 2006, p. 15 passim).

Evidentemente, não se pode falar na existência de metodologia de pesquisa em narrativas de viajantes e cronistas. Mas, dentre eles, alguns selecionaram, em suas observações, temas relevantes que coincidem com o interesse científico, seja no campo das ciências ambientais, seja no das ciências sociais. Depois da publicação de relatos de viagens, muitos pesquisadores utilizaram-nos no intuito de produzir conhecimento científico. Nas origens da Antropologia Social, sobretudo, na Inglaterra, os primeiros antropólogos se debruçaram sobre o material descritivo de missionários, funcionários e cronistas, constituindo assim o objeto de estudo da disciplina em seus primórdios uma etapa fundamental, que deve ser valorizada na história da Antropologia.

O viajante Richard Francis Burton é um bom exemplo: em seus livros, a seleção de temas e a descrição criteriosa favorecem a produção científica. Fornece-nos "pistas" que nos permitem localizar e aprofundar o conhecimento sobre temas relevantes para a ciência. Assim, em que pese sua condição de agente a serviço do processo de colonização, levada a efeito pela Inglaterra, Burton, com o aporte de informações etnográficas, deu uma valiosa contribuição para o desenvolvimento das Ciências Humanas e Ambientais no século XIX, inclusive para a Antropologia Social, que nas décadas seguintes aperfeiçoaria sua metodologia de pesquisa, produzindo conhecimento sistemático em favor da humanidade, sobretudo, a partir da obra de Bronislaw Malinowski, cujo trabalho de campo inaugurou um modelo de pesquisa para os antropólogos: o livro Argonautas do Pacífico Ocidental (1978) foi publicado originalmente em 1922.

A Sociologia e a História Ambiental são disciplinas que também se beneficiam dos conhecimentos legados pelos viajantes.

Exemplificaremos a contribuição de Burton para as Ciências Humanas, citando trechos de seu livro Viagem de canoa de Sabará ao Oceano Atlântico (1977), cujo conteúdo tem servido à produção de conhecimento acadêmico-científico nos dias atuais. Nosso interesse pela biografia e obra de Richard Francis Burton já dura algumas décadas. Nos anos 1980, durante o trabalho de pesquisa para dissertação de mestrado, estabelecemos um primeiro contato com a literatura dos viajantes, técnicos, cientistas e cronistas que percorreram ou trabalharam no Rio São Francisco dentre eles, o botânico Agustín Saint-Hilaire, os naturalistas J. B. von Spix e C. S. P. Martius, o engenheiro Henrique Fernando Halfeld, o policial militar Durval Vieira de Aguiar... e o Capitão Richard F. Burton. Nos dias atuais, retornamos a esses e a outros viajantes, sempre que necessário, visando a complementação de informações para a escrita de artigos e ensaios. Desta vez, Richard Burton é quem nos presta um auxílio essencial como o leitor poderá constatar nas páginas seguintes.

Em 18 de maio de 2016, proferimos no auditório do MHNJB - Museu de História Natural e Jardim Botânico/UFMG uma palestra cujo tema foi "Richard Francis Burton e sua viagem de canoa de Sabará ao Oceano Atlântico". 0 teor da palestra foi inteiramente incorporado a este artigo. Desejamos externar nossos agradecimentos às professoras Márcia Maria Duarte dos Santos e Maria Cândida Costa T. de Seabra, da UFMG / MHNJB, pela oportunidade de apresentarmos, naquela ocasião, o 
resultado do nosso trabalho a um público seleto de alunos e professores. Também estiveram presentes, naquela oportunidade, diversos associados efetivos do Instituto Histórico e Geográfico de Minas Gerais a quem agradecemos a participação nas discussões depois de concluída a palestra.

\section{Colonialismo e Antropologia}

Adam Kuper revela-nos as aspirações dos antropólogos em face do poder colonial, nos primórdios da constituição da Antropologia como ciência:

Desde os seus primeiros dias, a Antropologia britânica sempre gostou de se apresentar como uma ciência que poderia ser útil na administração colonial. As razões são óbvias. Os governos e interesses coloniais ofereciam as melhores perspectivas de apoio financeiro, sobretudo nas décadas anteriores ao reconhecimento da disciplina pelas universidades (Kuper, 1978, p. 121-122).

Mesmo depois de a Antropologia tornar-se uma disciplina universitária, os antropólogos acenavam para o Estado colonial com os conhecimentos de sua especialidade que poderiam beneficiar o Império em seu domínio sobre as colônias:

Os antropólogos, entretanto, apontaram os usos possíveis de sua disciplina como um meio de obterem reconhecimento. Os diplomas de Oxford, Cambridge e Londres eram justificados, em parte, como uma forma de fornecer treinamento para funcionários coloniais (Kuper, 1978, p. 123).

Argumentos que evidentemente visavam favorecer a empresa colonial - é importante reiterar. Mas vale reconhecer que certamente contribuíram para evitar traumas decorrentes do choque cultural nas colônias. Assim, o treinamento de funcionários que iriam lidar diretamente com os nativos tem aspectos positivos. Em seu trabalho como educadores, os antropólogos contribuíram para a superação de estereótipos, de manifestações etnocêntricas, que, sem os seus conhecimentos teóricos, teriam tornado o processo de colonização mais conflituoso. Provavelmente, a resistência dos nativos foi amenizada na medida em que houve a aprendizagem de noções e conceitos da Antropologia Social pelos funcionários coloniais, cujo trabalho amorteceu os embates entre colônia e Império. A questão da alteridade para os antropólogos: conhecer e reconhecer a cultura do outro. Certamente, evitaram-se assim chacinas e, até mesmo, práticas etnocidas e genocidas verificadas em tempos pretéritos como as denunciadas nos escritos de missionários e historiadores; por exemplo, no relato de Frei Martinho de Nantes (1979) e no livro de Tzvetan Todorov (1991). Reconhecemos que é difícil aquilatar quantitativamente o resultado do treinamento levado a efeito pelos antropólogos amenizando os entrechoques culturais.

Para a administração direta nas colônias, a Antropologia não contribuiu significativamente conforme o antropólogo Adam Kuper:

[...] até meados da década de 1930, pouco havia que se pudesse chamar uma antropologia oficial no Império Britânico e domínios. Tomando o Império como um todo, não é exagerado dizer que, por essa época, a contribuição antropológica direta para a administração era insignificante (Kuper, 1978, p. 127).

Essas primeiras intervenções dos antropólogos inauguram, a nosso ver, a prática humanística da Antropologia como ciência.

Em seus primórdios, a Antropologia Social se desenvolve fundamentando-se nos relatos de viajantes, cronistas, missionários etc. É a fase dos chamados "antropólogos de gabinete". Vale lembrar, por exemplo, a importância da obra $O$ ramo de ouro (1982), de Sir James Frazer, publicada originalmente em 1890 (doze volumes) - baseada em relatos diversos. Não se pode minimizar a importância desses estudos e investigações iniciais para a constituição da Antropologia como ciência.

O conceito fundador da Antropologia Social, considerado um marco histórico da disciplina, apareceria em 1871. Em seu texto A Ciência da Cultura, o inglês Edward Burnett Tylor assim o definiu: 
Tomado em seu amplo sentido etnográfico, (cultura) é este todo complexo que inclui conhecimentos, crenças, arte, moral, leis, costumes ou qualquer outra capacidade ou hábitos adquiridos pelo homem como membro de uma sociedade (Tylor apud Castro, 2005, p. 69).

Os esclarecimentos de Tylor são importantes para melhor entendermos o referido conceito: "Assim como o catálogo de todas as espécies de plantas e animais de um distrito representa sua flora e fauna, a lista de todos os itens da vida geral de um povo representa aquele todo que chamamos sua cultura." (Tylor apud Castro, 2005, p. 77-78) 0 modelo inicial são as ciências da natureza. Na visão do autor, diversos itens da vida formam a cultura. Subjacente à definição de Tylor, já se pode perceber a importância que a Antropologia concede à aprendizagem e transmissão da cultura. Neste particular, vale lembrar os conceitos de enculturação e socialização que posteriormente seriam desenvolvidos. Ao refletir mais detidamente sobre o "todo complexo", é possível pensar também no enfoque sistêmico tão valorizado nos estudos antropológicos, e que também seria desenvolvido a posteriori. A nosso ver, a partir da definição de cultura, a Antropologia Social cresce em busca de maior imparcialidade e objetividade.

Torna-se necessário aprofundar os estudos sobre a relação entre a Antropologia Social, em suas origens, e o colonialismo. E também debruçar-nos sobre textos como este, a seguir, de Lévi-Strauss:

A nossa ciência atingiu a maturidade no dia em que o homem ocidental começou a perceber que jamais se entenderia a si mesmo enquanto houvesse um único povo ou raça na superfície da Terra que ele tratasse como um objeto. Só então a Antropologia poderia apresentar-se em suas verdadeiras cores: [...] levar o humanismo a toda a humanidade (Lévi-Strauss, 1978, p. 121).

Uma vertente da Antropologia desenvolver-se-ia no século XX imbuída de uma prática transformadora da realidade social. Vale conhecer a opinião do Professor Roberto Cardoso de Oliveira sobre o potencial da Antropologia nesse particular:

Por que a antropologia prática não poderia cumprir uma função terapêutica no diálogo interétnico? Creio ser esta uma das principais funções que nos cabe exercer enquanto tradutores - melhor ainda: intérpretes - de idiomas culturais em confronto (Cardoso de Oliveira, 2004, p. 30).

Nos dias atuais, esse potencial é levado à prática. A Antropologia presta relevantes serviços à humanidade, sobretudo, no campo dos direitos humanos. Em contatos interétnicos, sua mediação torna-se, a cada momento, mais relevante. Como exemplo, vale pensar na importância dos laudos antropológicos que têm sido requisitados pelos tribunais de justiça para dirimir situações de conflito/litígio entre, de um lado, povos tradicionais (índios, quilombolas, lavradores etc.) e, de outro, grileiros, latifundiários, madeireiros. Outros exemplos poderiam ser mencionados. Há a contribuição da Antropologia e de outras ciências humanas para a formação e o trabalho de profissionais do Serviço Social e de outras especialidades.

\section{Richard F. Burton: breve perfil}

Por suas próprias características de personalidade, Richard Burton era um homem vocacionado para o trabalho em áreas inóspitas conforme suas próprias palavras:

Meu velho anseio pelos prazeres da vida nas matas distantes - a solidão - pesou forte sobre mim. Suspirava impaciente para ficar novamente longe dos meus semelhantes, por assim dizerpara mais uma vez ficar frente a frente com a Natureza. Esse alimento da alma, como dizem os árabes, é o verdadeiro antídoto da entourage de cada um, dos efeitos perniciosos da época e da raça do indivíduo, e ele é generoso para quem deseja pensar com a própria cabeça (Burton, apud Rice, 1993, p. 401).

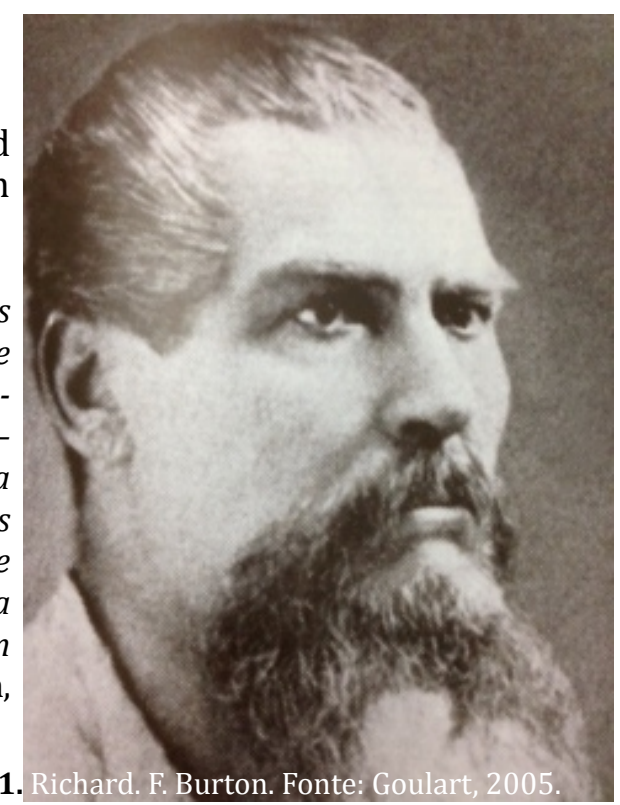

Figura 1. 
Era um homem da ordem, fiel defensor do status quo conforme se depreende da leitura de sua biografia, escrita pelo jornalista Edward Rice. Em sua vida de viagens e investigações, surpreendem os sacrifícios a que se submeteu a serviço do Reino Unido:

Burton se distinguia em qualquer grupo, exceto quando estava deliberadamente trabalhando como agente, disfarçado entre os povos das terras em processo de anexação pela Inglaterra. Com sua altura marcante de 1,80 metro, peito largo, corpo esguio e rijo, olhos de 'cigano' e uma bela aparência morena, ele tinha um ar imponente e orgulhoso, com a cicatriz na face deixada por um feroz golpe de lança que sofreu numa batalha contra saqueadores somális (Rice, 1993, p. 19).

Enfrentou as maiores dificuldades e provações em seu trabalho como capitão do exército e agente secreto, seja em sua peregrinação a Meca, com seu disfarce de muçulmano, seja em sua expedição às nascentes do Rio Nilo ou em sua viagem pelo Vale do São Francisco no Brasil.

Mas era também um intelectual voltado para estudos que pouco interessavam à coroa britânica. Para sabermos um pouco mais sobre a sua biografia, é importante conhecermos um personagem histórico que ele muito admirava: Luiz Vaz de Camões. Nesse particular, pode-se falar numa identificação de Burton com a personalidade do eminente poeta. Durante 35 anos, estudou sua obra. Traduziu Os Luzíadas e escreveu e publicou dois volumes de comentários sobre o grande vate lusitano e seus escritos. Seguiu os passos do poeta, visitando Goa e outros lugares do Oriente onde ele esteve.

A admiração de Burton relativamente à vida e obra de Camões é assim resumida por seu biógrafo:

[...] Os Luzíadas, poema épico que exalta as conquistas dos portugueses e seus grandes feitos [...]. Foi esse tema romântico, dramático, heróico, que tanto fascinou Burton, da lavra de um homem (Camões) que, como também ocorria em seu caso, viveu de fato a vida posta na obra (Rice, 1993, p. 155).

A exemplo de sua própria vida, atribulada e marcada pela aventura, não passou despercebida a Burton a trajetória do poeta:

Começando com as mais belas e brilhantes promessas, exposto na maturidade às mais extremas vicissitudes, a intensos prazeres e a 'abismos terríveis', passando na meia-idade para o cansaço das esperanças frustradas e terminando relativamente cedo no mais profundo fosso da desilusão, da angústia e da indigência, o Estudioso, o Soldado, o Viajante, o Patriota, o Poeta, o Poderoso Gênio, assim reunidos numa única vida, [...] Visto sob essa luz, o português pode ser considerado único; nunca existiu um tal espírito tão maltratado pela Fortuna (Burton, apud Rice, 1993, p. 154).

Certamente, Burton percebeu similitudes entre sua vida e obra e a biografia de Camões incluindo, nesse particular, a ação do soldado, a trajetória do viajante e aventureiro, as paixões do homem, sem perder de vista evidentemente a obra genial do poeta português.

Podemos pensar, com alguma convicção, que a obra de Richard Burton não revelava apenas e tão-somente o interesse da Coroa britânica.

Algumas transgressões de regras e normas sociais predominantes na sociedade inglesa podem ser observadas tanto na vida quanto na obra de Sir Richard Francis Burton. A primeira, de natureza pessoal, porém, com alguma repercussão em seu tempo e em seu meio:

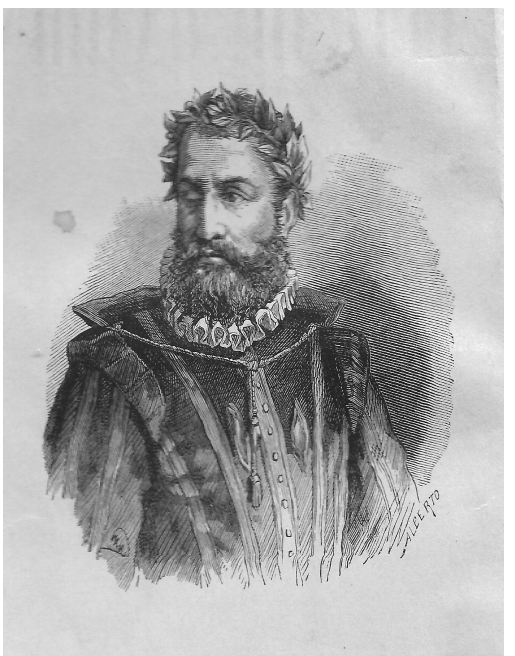

Figura 2. Camões. Fonte: Wikipédia. 
Numa época em que os católicos na Inglaterra eram considerados cidadãos de segunda categoria, apesar das leis aprovadas em favor de sua emancipação, Burton se casou com uma católica inglesa, Isabel Arundell. [...] Assim, esse casamento rompeu barreiras mais formidáveis do que os desertos e os nômades beduínos que Burton enfrentou na viagem a Meca ou nos pântanos miasmáticos que atravessou na África Central. A Inglaterra vitoriana criticava acerbamente lady Burton, e os preconceitos que a rodeavam ainda repercutem em alguns textos atuais sobre seu marido (Rice, 1993, p. 23).

Dona Isabel seguiu o marido em suas ações ousadas não só na Inglaterra, mas em outros países. Senão, vejamos:

[Em São Paulo] Isabel tinha uma capela onde, com a permissão do bispo local, pregava para os escravos negros, que, pelo que ela descobriu, haviam sido criados com a ideia de que, por serem negros, não tinham alma, erro que ela se empenhou ao máximo em corrigir (Rice, 1993, p. 395).

Aqui deve ser ressaltado o catolicismo humanista de Dona Isabel Arundell Burton, cuja admiração pelo trabalho do marido a levou a escrever o livro The Life of Captain Sir Richard F. Burton (1893). 0 conteúdo desta obra foi relevante como fonte para a biografia mais importante de Richard Burton, ou seja, o livro de Edward Rice que ora comentamos.

Vale acrescentar que o cônsul Richard Francis Burton poderia ter escravos no Brasil, se assim o desejasse. Mas preferiu remunerar seus empregados como homens livres (Rice, 1993, p. 395). Assim, a atitude de Dona Isabel para com os escravos certamente contava com o apoio de seu marido.

Católica praticante, Isabel dedicou-se a obras sociais no Brasil:

[...] ficou transtornada com a pobreza generalizada que via em torno, e com a indiferença em relação à miséria (o padre local era um desses indiferentes). Assim, ela reservou um espaço no andar térreo do convento, para oferecer comida e abrigo aos pobres durante a noite (Rice, 1993, p. 395).

Outra transgressão cometida pelo militar e agente secreto Richard Francis Burton teve grande repercussão em sua época. Baseado em seu conhecimento de outras culturas, escreveu sobre a sexualidade feminina, sobretudo, sobre o prazer sexual feminino (Rice, 1993, p. 22). Nesse particular, deve-se ressaltar sua vocação para o conhecimento de outras culturas. Burton entrou em contato com a literatura do Oriente; leu e introduziu

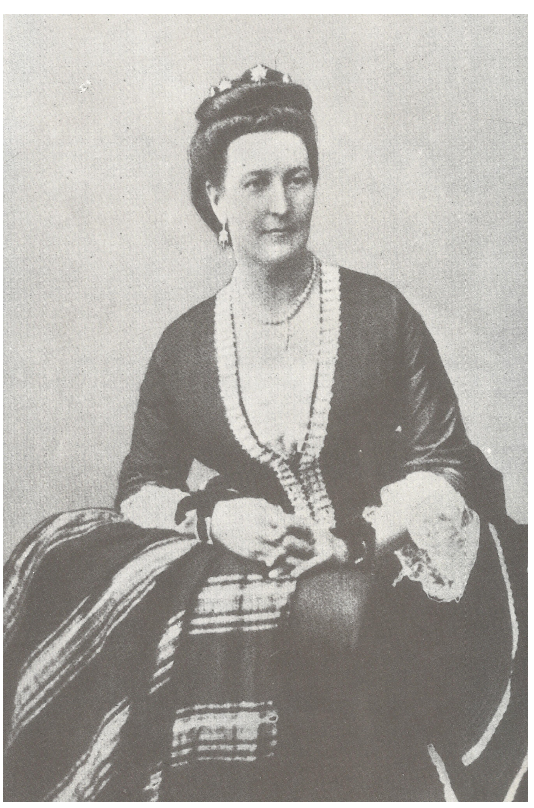

Figura 3. Isabel Arandell Burton. Fonte: Rice, 1993. na Inglaterra vitoriana - vale ressaltar! - obras eróticas como o Kama Sutra, o Jardim Perfumado e Ananda Ranga, contribuindo para a transformação de normas e regras de convívio social em seu país e para "o surgimento de novas posturas em relação ao sexo no mundo ocidental" (Rice, 1993, p. 22). Esse é um papel social frequentemente desempenhado por antropólogos em seu trabalho, que obviamente inclui os relatos etnográficos: levar à sua sociedade de origem o conhecimento sobre outras culturas.

Em que pese o preconceito, os estereótipos, as manifestações etnocêntricas, presentes em alguns textos de sua autoria, a obra de Burton deve ser considerada sob o ponto de vista etnográfico. Evidentemente, ao ler os seus escritos, não se deve perder de vista a indispensável contextualização, ou seja, o conhecimento sobre a sociedade e o tempo nos quais ele viveu e escreveu.

A experiência de campo desenvolvida por Burton resultou em relatos minuciosos que certamente foram relevantes para a Antropologia em seus primórdios: 
[...] estudos sobre usos e costumes de povos primitivos e semibárbaros, alguns dos quais já desaparecidos [...]. Possuía uma imensa compreensão da vida nativa. Foi um pioneiro em estudos etnológicos e pode ser equiparado ao grande americano Lewis Henry Morgan [...] (Rice, 1993, p. 21).

É possível mencionar a sua contribuição etnográfica, porém, é temerário falar em "estudos etnológicos". A Etnologia interpreta (ou, como querem outros, analisa) informações provenientes de pesquisas sobre grupos étnicos. Em geral, trata-se de estudos sistemáticos em que se utiliza um instrumental teórico (por exemplo, conceitos e noções) sem se perder de vista as normas estabelecidas para a pesquisa de campo e documental. Enfim, considera-se relevante a metodologia de pesquisa.

O conhecimento de Burton sobre outras culturas foi facilitado pela sua aptidão para a aprendizagem de línguas. Em suas andanças por três continentes, seja como agente secreto, seja como diplomata, aprendeu vinte e nove línguas e vários dialetos. Tornou-se um profundo conhecedor do sufismo, uma variante do Islamismo. No Brasil, interessou-se pelo estudo de línguas indígenas, escrevendo uma gramática do Tupi-Guarani, porém, não publicada. (Rice, 1993, p. 399)

Certamente, a obra de Burton e de outros viajantes foi fonte valiosa para os chamados "antropólogos de gabinete" nos primórdios da Antropologia. Esses precursores da Antropologia como ciência devem ser valorizados pelo seu trabalho pioneiro.

Cônsul em São Paulo, Burton exercia também sua função de agente secreto a serviço do Império:

Sempre em busca de ouro, Burton ouviu falar de uma mina no Estado de Minas Gerais. [...] Aparentemente, a viagem pelas matas brasileiras seria apenas por curiosidade e aventura, mas, ao que parece, incluía uma missão secreta de Burton, pois o governo britânico tinha interesse em encontrar áreas despovoadas para poder colonizá-las (Rice, 1993, p. 399).

Sua missão incluiu uma visita à Mina de Morro Velho, explorada por uma empresa britânica sob a direção de um certo Mr. Gordon. Burton desceu ao fundo da mina numa caçamba, em companhia de Dona Isabel, sua esposa. No dia seguinte, houve um acidente com mineiros que haviam descido na mesma caçamba - todos morreram. Alguns meses depois, o filho predileto do Mr. Gordon faleceu "triturado" por uma máquina na mina (Rice, 1993, p. 400-401).

Burton trabalhou no Brasil durante a guerra da tríplice aliança contra o Paraguai, país visitado por ele durante o conflito, conforme Edward Rice:

[...] a guerra rapidamente se transformou numa luta entre, como disse Burton, 'uma nacionalidade obscura,' 'uma humanidade paleolítica', que combatia com rifles de um único tiro, uma marinha composta basicamente de chalanas e canoas, e a máquina militar altamente industrializada dos aliados, que dispunha dos modelos mais recentes dos rifles Spencer $e$ Enfield e de couraçados (Rice, 1993, p. 403).

Do ponto de vista bélico, a desproporção é mais do que evidente.

A máquina militar mortífera arrasou o país, dizimando grande parte da população nativa, sobretudo, a população masculina:

O Paraguai teve que convocar às armas todos os homens válidos - havia regimento de garotos entre doze e quinze anos, e até batalhões de mulheres - e quando a guerra terminou, em 1870, o país tinha perdido 80\% de sua população de 1,3 milhão de pessoas; restaram apenas 28.700 homens vivos (Rice, 1993, p. 403).

Fica muito bem caracterizada a estupidez da guerra - a prática do genocídio. A vitória coube aos aliados, mas, certamente, os louros da glória são hoje reconhecidos aos patriotas paraguaios para quem valoriza o patriotismo. 
Os aliados venceram, porém, foi feroz a luta e a resistência dos paraguaios. Fundamentando-se no relato de Richard Burton, Rice refere-se ao povo paraguaio com admiração: "a tenacidade de um buldogue", "uma obstinação nos propósitos, [...] uma bravura selvagem e uma resistência desesperada raras nos anais da humanidade" (Rice, 1993, p. 403).

Os escritos de Burton contribuíram para fundamentar o trabalho de interpretação de historiadores da guerra.

\section{A longa travessia}

Nesta seção, pretendemos exemplificar a importância de alguns trechos do livro Viagem de canoa de Sabará ao Oceano Atlântico, de Richard F. Burton (1977), como informação etnográfica em sua época e, a posteriori, como material de interpretação para as ciências sociais que se desenvolveriam no Brasil como a História, a Antropologia Histórica, a Sociologia, a Geografia Humana, a Geografia Cultural etc. Não se pode perder de vista também sua contribuição para as ciências ambientais.

Estamos cientes de que o texto de Burton está repleto de manifestações etnocêntricas, estereótipos etc. Mais uma vez, lembramos que não é possível uma visão imparcial de seus relatos sem a devida contextualização.

Em 7 de agosto de 1867, Richard Francis Burton inicia sua viagem em Sabará [MG] com o intuito de percorrer mais de 3.000 quilômetros, navegando no Rio das Velhas e no São Francisco. A descrição da viagem está em seu livro acima mencionado.

Acostumado, de alguma forma, ao conforto que as empresas de navegação a vapor já ofereciam aos passageiros em suas viagens pelo mundo, Burton surpreende-se com a qualidade da embarcação em que faria a longa travessia no vale são-franciscano:

Encaminhamo-nos ao Porto da Ponte Grande, onde se encontrava o ajoujo ou balsa. Jamais vira embarcação tão decrépita, verdadeira arca de Noé, semelhante a uma carroça de ciganos flutuante, coberta por um toldo, cerca de dois metros e trinta centímetros de altura e um de comprimento, assentando-se sobre dois troncos ocos. $O$ rio devia ser bem seguro, para que uma geringonça daquelas navegasse sem acidente (Burton, 1977, p. 13).

Durante a viagem, Burton ameniza suas referências à embarcação certamente ao conhecer sua utilidade para os povos ribeirinhos: "O ajoujo comum é uma junção de duas ou três canoas, sendo que, quando três, a mais comprida deve ficar no centro. [...]" (1977, p. 14 passim).

A seguir, o leitor terá a oportunidade de verificar como era construído um ajoujo na primeira metade do século XX. A citação fundamenta-se na obra do engenheiro e cientista Henrique Guilherme Halfeld (1860, p.1) e em entrevistas concedidas por velhos navegantes do São Francisco:

Embarcação do Rio São Francisco formada por duas ou três canoas emparelhadas e unidas entre si por paus roliços, que eram colocados sobre as mesmas transversalmente, fazendo-se amarras com tiras (ou cordas) de couro cru. Por cima dos paus, colocava-se um estrado e uma cerca de madeira, onde pessoas, animais e mercadorias podiam viajar com segurança (Neves, 2013, p. 15).

Ao entrar em contato com os primeiros vestígios da caatinga na área de transição entre esse bioma e o cerrado, Burton lembra-se do Rio das Velhas:

Não é preciso dizer que nos lembramos com saudade da encantadora paisagem do Rio das Velhas: o ar claro, límpido e rico em oxigênio, o esplêndido cenário das florestas nas margens desertas, a música das aves e de outros animais, mesmo o ruído das cachoeiras e das corredeiras, e a alegria da Natureza em geral (Burton, 1977, p. 207).

Provavelmente, as "florestas nas margens desertas" eram formadas por exemplares de árvores

(C) Labor \& Engenho, Campinas [SP] Brasil, v.11, n.1, p.70-82, jan./mar. 2017. 
da Mata Atlântica. Ainda hoje há espécimes remanescentes da Mata Atlântica em Minas Gerais, por exemplo, no parque estadual do Caraça.

Com referência às noites no mês de agosto, o mesmo autor não economiza elogios: "[...] são suaves, serenas, deliciosas" (Burton, 1977, p. 49).

Mas os fornos da mineração já contribuíam para dizimar as matas ciliares e de encosta:

[...] encontramos o barco "Jaguara", carregando enormes troncos seculares para Morro Velho. Essa grande embarcação chata, com 34 metros e meio de comprimento por $14 e$ meio de largura e outro tanto de pontal, construída com vinhático e canela, com rebordo de pau d'arco e fundo forrado de ferro, é triangular na proa e na popa. Seu peso é de aproximadamente 16.000 quilos, correspondendo a maior parte ao metal. Descarregada, tem o calado de dez centímetros, que aumenta cerca de dois centímetros e meio para cada quatro toneladas; transporta 72 toneladas descendo o canal, de 55 centímetros de profundidade, entre Macaúbas e Jaguara, e vai deste último lugar a Sabará em doze dias, regressando em dois ou três (Burton, 1977, p. 17).

As medidas e a capacidade de transporte do "Jaguara" eram verdadeiramente consideráveis. Ainda assim, o Rio das Velhas fornecia condições de navegabilidade para uma embarcação desse porte.

Em 1869 foi lançada a primeira embarcação a vapor no Rio das Velhas: o "Saldanha Marinho" (Neves, 2006, p. 32). Mas, em algumas décadas, aquele tributário do São Francisco tornou-se impróprio para a navegação. Desprotegidas as margens do rio, o assoreamento alcança o canal navegável, impedindo o tráfego de embarcações a vapor. Em outubro de 1898, o projeto da navegação do Rio das Velhas foi definitivamente abandonado (Neves, 2006, p. 30). Além dos obstáculos naturais como corredeiras e cachoeiras, deve-se considerar como uma das causas o assoreamento.

Nos dias atuais, a histórica e persistente degradação do Rio das Velhas motivou a UFMG a lançar o Projeto Manuelzão, que visa a revitalização daquele importante afluente do São Francisco.

Entre Januária e Carinhanha, Burton foi surpreendido pelo furor de uma tempestade são-franciscana:

Foi uma noite abominável. A tempestade, como frequentemente acontece no Brasil, assumiu a forma de um ciclone, rodando do norte, passando pelo leste, para o sul, e houve momentos em que pensei que o toldo do (ajoujo) 'Elisa' fosse ser arrancado pelo vento e pela chuva (Burton, 1977, p. 219).

O texto acima citado foi fundamental para comprovarmos a veracidade dos relatos de velhos navegantes (remeiros) que entrevistamos nos anos 1980, durante o trabalho de campo para a escrita de nossa dissertação de mestrado. Os pés de vento e tempestades colocavam em risco suas embarcações.

Nas proximidades de Morrinhos (atual Matias Cardoso), o viajante reencontrou a bonança:

Depois de uma hora de trabalho, encontramos local para ancoragem perto da Ilha do Carculo. À noite, vimos as estrelas e os planetas como se fossem os rostos de amigos há muito tempo ausentes (Burton, 1977, p. 221).

Nas proximidades da foz do afluente Verde Grande:

As terras baixas junto ao rio são, periodicamente, cobertas pelas cheias [...]. Os brejos, posteriormente, secam ou tornam-se nateiros, isto é, lamaçais. São feitas, nas ipueiras, rendosíssimas pescas (Burton, 1977, p. 223).

No "lameiro" (conforme a linguagem regional) fertilizado pelo húmus natural levado pelo rio, plantava-se cereais, tubérculos e verduras. Eram as "culturas de vazante". As colheitas eram abundantes e fartas, alimentando o vazanteiro e sua família. 0 excedente, que não se destinava à acumulação, 
era vendido ou trocado por outros produtos no comércio ambulante realizado pelas barcas. As barragens alteraram a vazão das águas do São Francisco, e, em consequência, a formação de lagoas marginais, ipueiras e brejos.

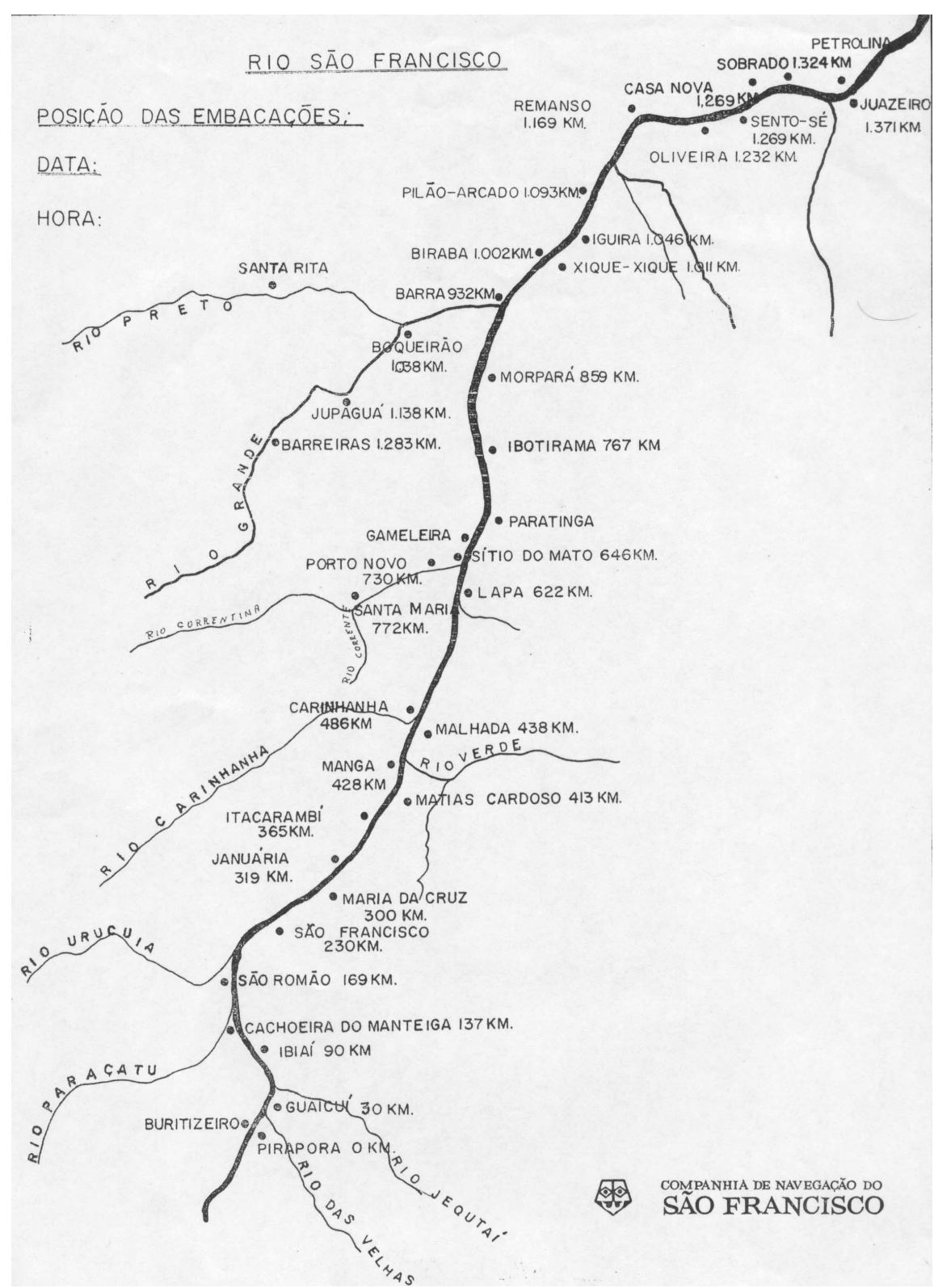

Figura 4. Mapa histórico do Médio São Francisco (Anos 1960) antes da construção da Barragem de Sobradinho. Fonte: Companhia de Navegação do São Francisco. Pirapora [MG].

Assim, a nosso ver, as informações do viajante inglês possuem alguma importância para as Ciências Ambientais.

Como se fosse um antropólogo atento ao seu ofício, Burton registra termos, usos e costumes regionais:

Durante a última noite, um forte vento sul começara a soprar das montanhas, avisandonos de que iria cair chuva. Era o começo da estação chuvosa, mas o povo chama essas primeiras chuvas de chuvas da queimada. Em toda a parte, acredita-se que as queimadas chamam as chuvas (Burton, 1977, p. 170).

Essa crença (e prática) dos roceiros ribeirinhos certamente contribuiu para a destruição de ecossistemas são-franciscanos. As queimadas descontroladas destroem os nutrientes do solo conforme nos ensinam os especialistas em Ciências Ambientais. 
Referindo-se aos tripulantes do ajoujo "Elisa" que, junto com ele, embarcaram no Rio das Velhas, Burton menciona também os remeiros e mestres do Rio São Francisco: "Os tripulantes (contratados em Sabará) pareciam marinheiros de primeira viagem, nem de longe lembravam os hábeis navegantes do São Francisco" (Burton, 1977, p. 15). Os elogios do autor são confirmados em relatos mais precisos ao longo de sua viagem:

[...] manejando o remo como a nadadeira de um monstruoso peixe e firmemente plantado na popa da canoa da balouçante e sacolejante embarcação, ele (Manuel Cipriano) se curvava de leve para a frente, olhava, fixa e tensamente, o sombrio paredão para o qual estávamos sendo arrastados a uma velocidade de vinte nós por hora e, graças a alguns engenhosos toques no leme, no momento exato, fazia a proa curvar-se, quase raspando o rochedo (Burton, 1977, p. 305).

Informações relevantes para a nossa pesquisa sobre os remeiros nos anos 1980.

Durante a longa travessia, Burton transmite-nos informações sobre a índole de alguns remeiros com quem ele teve oportunidade de interagir na embarcação sem perder de vista também a referência a um componente da cultura popular tradicional da região:

Mariano (remeiro) cantava bem, tinha um repertório imenso e, como repentista, adquiriu fama local [...] adotara o nome poético e arcádico de Manjericão (Burton, 1977, p. 305).

As canções fluviais, como as toadas e cocos, favoreciam o desempenho dos tripulantes no trabalho, e eram amplamente difundidas na região. Os temas variavam: o amor, a mulher, a sátira aos potentados e às cidades e aos povoados (Neves, 2011, Cap. VIII).

Durante o nosso trabalho de campo, os relatos de Burton foram confrontados com o teor das entrevistas concedidas por remeiros e mestres.

Ao chegar à embocadura do Rio das Velhas, o viajante inglês decide subir o Rio São Francisco para conhecer a cachoeira de Pirapora. Apenas 28 quilômetros separam as duas localidades:

Pirapora era diferente de tudo que havíamos visto até então; é um artigo superior em qualidade, como em quantidade. É, na verdade, em parte, uma cachoeira de verdade, dividida em duas seções (Burton, 1977, p. 169).

Com o pensamento sempre voltado para as novas tecnologias, Burton pensou em obras de engenharia, como o derrocamento do "obstáculo", para favorecer a navegação a vapor. Mas o que se deve ressaltar em sua descrição é a existência da cachoeira:

$A$ [cachoeira de] Pirapora constitui um sério obstáculo. Não é irremovível, mas removêla custaria muito dinheiro e levaria mais tempo do que para se fazer o mesmo com todas as obstruções mais sérias existentes no Rio das Velhas (Burton, 1977, p. 170).

As diversas intervenções do homem na cachoeira de Pirapora, durante a construção da Ponte Marechal Hermes e, posteriormente, para calçamento de ruas, praças e avenidas e para a exploração de brita, transformaram-na numa corredeira conforme se pode perceber na Figura 5.

\section{Considerações Finais}

Adam Kuper demonstra-nos a relação entre o Estado colonial e a Antropologia Social em suas origens. Conforme esse autor, a Antropologia pouco contribuiu para a administração direta do Estado colonial na África, Ásia e Oceania, porém, teria havido alguma colaboração de antropólogos no treinamento de funcionários que atuaram nas colônias. A nosso ver, deve-se interpretar com outros critérios essa relação entre a Antropologia e o colonialismo: certamente, o treinamento de funcionários contribuiu para amenizar choques culturais traumáticos (chacinas, etnocídio, genocídio etc.) a exemplo de experiências anteriores, em séculos precedentes, mencionadas por missionários, cronistas e historiadores. Mas evidentemente não se pode perder de vista a dominação do Estado colonial. 


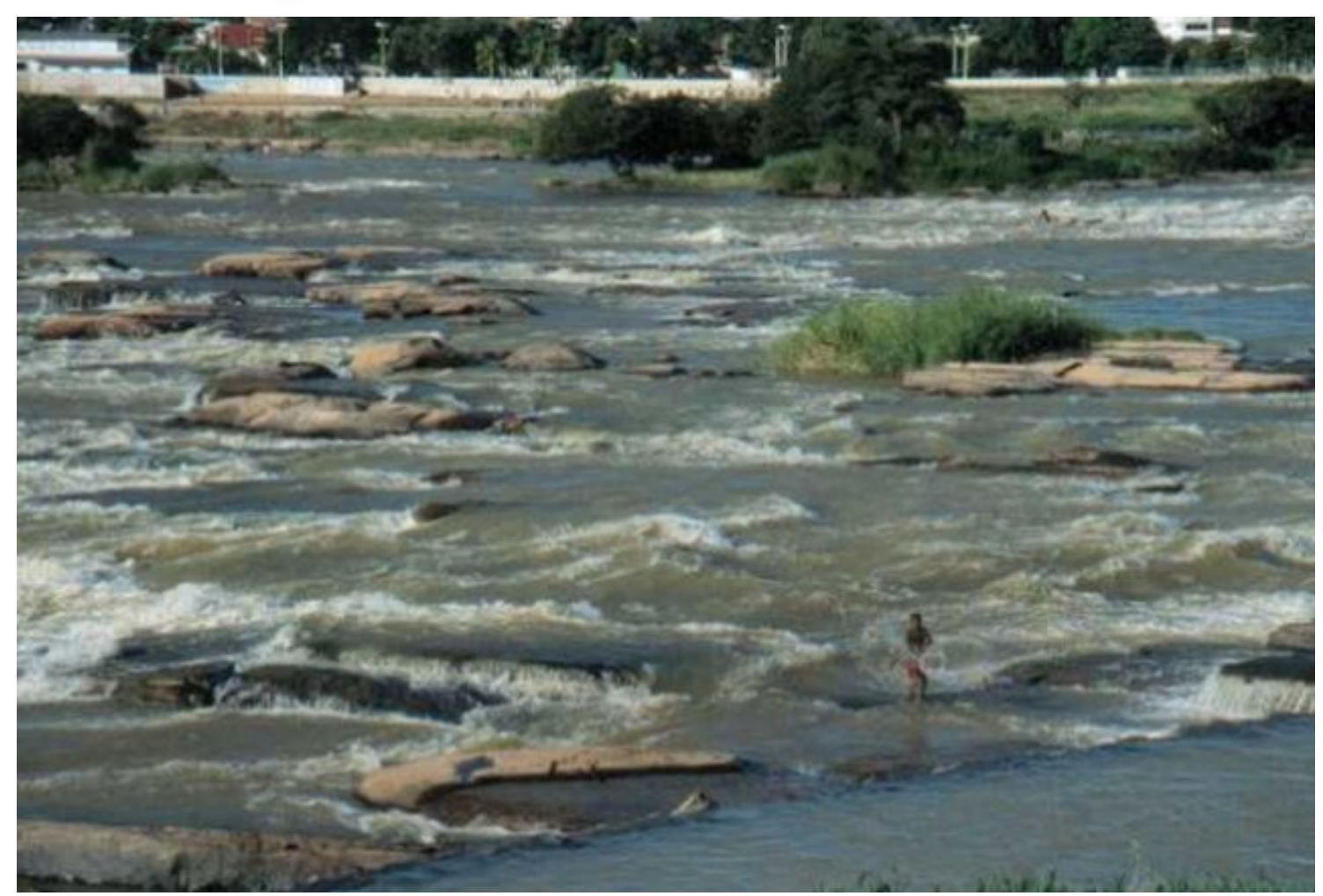

Figura 5. Cachoeira de Pirapora, rio São Francisco. Foto: Anônimo.

A contribuição de viajantes, missionários e cronistas para a formação do pensamento antropológico em seus primórdios é reconhecida, sobretudo, para o trabalho dos chamados "antropólogos de gabinete".

Richard Francis Burton é um dos viajantes que tem contribuído com informações etnográficas para o campo das Ciências, incluindo Antropologia Histórica, a História Ambiental e a Sociologia Ambiental. Entre outras obras, sua Viagem de canoa de Sabará ao Oceano Atlântico serve ainda hoje à produção do conhecimento científico.

\section{Referências}

Burton, R. F. (1977). Viagem de canoa de Sabará ao Oceano Atlântico (D. Jardim Jr., Trad.). (Coleção Reconquista do Brasil). Belo Horizonte: Ed. Itatiaia.

Cardoso de Oliveira, R. (2004). "O mal-estar da ética na antropologia prática”. In C. Víctora, R. G. Oliven, M. E. Maciel, \& A. P. Oro (Orgs.). Antropologia e ética - o debate atual no Brasil. Niterói: EdUFF.

Castro, C. (Org). (2005). Evolucionismo cultural - Textos de Morgan, Tylor e Frazer (Coleção Antropologia Social). Rio de Janeiro: Jorge Zahar Editor.

Frazer, J., Sir (1982). O ramo de ouro. Rio de Janeiro: LTC. [originalmente publicada em 1890].

Goulart, E. M. A. (Org.). (2005). Navegando o Rio das Velhas, das minas aos gerais. Belo Horizonte: Instituto Guaicuí-SOS Rio das Velhas / Projeto Manuelzão-UFMG.

Halfeld, H. G. F. (1860). Atlas e relatório concernentes à exploração do Rio São Francisco desde a Cachoeira de Pirapora até o Oceano Altântico. Rio de Janeiro: [s.n.].

Kuper, A. (1978). Antropólogos e Antropologia (A. Cabral, Trad.) (Coleção Ciências Sociais). Rio de Janeiro: Editora Francisco Alves. 
Lévi-Strauss, C. In A. Kuper (1978). Antropólogos e Antropologia (A. Cabral, Trad.) (Coleção Ciências Sociais). Rio de Janeiro: Editora Francisco Alves.

Malinowski, B. (1978). Argonautas do Pacífico Ocidental (2a ed.). (A. P. Carr \& L. A. C. Mendonça, Trad.) (Coleção Os pensadores). São Paulo: Abril Cultural.

Nantes, M. de, Padre. (1979). Relação de uma missão no Rio São Francisco (Barbosa Lima Sobrinho, Trad. e comentários). São Paulo: Cia. Editora Nacional; Brasília: INL.

Neves, Z. (2006). Na carreira do Rio São Francisco. Trabalho e sociabilidade dos vapozeiros (Coleção Reconquista do Brasil, Vol. 237 2ª série). Belo Horizonte: Ed. Itatiaia.

Neves, Z. (2013). Médio São Francisco. Os homens do rio, sua linguagem, seu saber. Belo Horizonte: Núcleo de Estudos do Vale do São Francisco, Caderno no 2.

Rice, E. (1993). Sir Richard Francis Burton. O agente secreto que fez a peregrinação a Meca, descobriu o Kama Sutra e trouxe As Mil e uma Noites para o Ocidente. (2a ed.). (D. Bottmann, Trad.). São Paulo: Companhia das Letras.

Todorov, T. (1991). A conquista da América - A questão do outro (3a ed.). (B. P. Moisés, Trad.). São Paulo: Ed. Martins Fontes.

Tylor, E. B. "A ciência da Cultura" (1871) In C. Castro (Org.). [2005]. Evolucionismo cultural - Textos de Morgan, Tylor e Frazer (Coleção Antropologia Social). Rio de Janeiro: Jorge Zahar Editor.

\subsection{Observação}

O autor assume inteira responsabilidade pela divulgação das imagens que integram este artigo. 